\title{
Central Composite Design Method for the Preparation, Stability and Properties of Water-in-Diesel Nano Emulsions
}

\author{
Ali Ghufran Khidhir, Adel Sharif Hamadi* \\ Department of Petroleum Technology, University of Technology, Baghdad, Iraq \\ Email: ^adel_al_obaidi@yahoo.com
}

How to cite this paper: Khidhir, A.G. and Hamadi, A.S. (2018) Central Composite Design Method for the Preparation, Stability and Properties of Water-in-Diesel Nano Emulsions. Advances in Chemical Engineering and Science, 8, 176-189.

https://doi.org/10.4236/aces.2018.83012

Received: June 10, 2018

Accepted: July 22, 2018

Published: July 25, 2018

Copyright (๑) 2018 by authors and Scientific Research Publishing Inc. This work is licensed under the Creative Commons Attribution International License (CC BY 4.0).

http://creativecommons.org/licenses/by/4.0/

\begin{abstract}
Water in diesel nano-emulsion (WiDNE) due to their nano size, kinetically stable gives its beneficial in commercial and environmental aspects. However, the capability of this fuel strongly depends on the method of preparation, stability and their physic-chemical properties. Central composite design (CCD) method was used to optimize variable interactions in order to obtain maximum stability. Methodology RSM method with six independent variables was selected in order to understand the impacts on droplet size. The response surface and 3D plots of the quadratic polynomial model were created for studying the combination effect on response. Dynamic light scattering DLS technique was used for measuring of droplet sizes. The analysis result by ANOVA was with $95 \%$ confidence displaying F value model was 52.82 . The results displayed model was fulfilled with the assumptions of ANOVA. This study has relied on Design Expert software to locate the optimum droplet size situations. The measured diameter is $26 \mathrm{~nm}$, with 0.0297 errors between actual conditions and measured value. The optimum blend properties of prepared WiDNE fuel were compared with conventional diesel. Improvements in physical properties were observed in presence of water in WiDNE.
\end{abstract}

\section{Keywords}

Water in Diesel, Optimization, Central Composite Design, Stability

\section{Introduction}

Emulsions consist of two immiscible liquids which one as small droplets in the dispersed liquid, and can be classified as oil-in-water or water-in-oil relying on which phase is constituting the disperse phase [1] [2] [3]. 
Nano-emulsion is a class of high stability emulsions with extremely small droplets in the range of $20-200 \mathrm{~nm}$ with no apparent flocculation or coalescence [4], and this makes them a useful applications for example in the pharmaceutical, cosmetics, agrochemicals, and in the chemical industries [5] [6] [7] [8] [9].

The most common process in the preparation of nanoemulsions is high energy method [10]. Recently also a neat low-energy method [11] has been developed, by taking advantage of phase behavior and properties, to promote the formation of ultra-small droplets. These low energy techniques include self-emulsification [12] [13], phase transition [1] [14] [15] and Phase Inversion Temperature methods (PIT) [16] [17].

In this study, WiDNE fuel preparation by using high shearing method. The emulsification process includes simulating droplet model for the optimum condition based on the Central Composite Design (CCD) [18] [19]. Consequently, CCD method is the best for illustration of these influences [20]. Both of the droplets size and distributions inside the WiDNE fuel were measured through DLS technique.

The path for implementing experimental design was evaluated for two purposes. The first is to identify a subset of the original processes factors that have substantial main and interaction impacts on the final WiDNE fuel properties achieved. Second, factors have to be significant optimized statistically to determine the best WiDNE properties, according to the assumed Response Surface Method (RSM) model.

\section{Materials and Methods}

\subsection{Materials}

\subsubsection{Diesel Fuel}

Conventional diesel fuel produced from local Daura Refinery was used as continuous phase of WiDNE fuel. The characterization of diesel fuel is shown in Table 1.

Table 1. Characterization of diesel fuel.

\begin{tabular}{ccc}
\hline No. & Properties & Value \\
\hline 1 & Density at $15 \% .(\mathrm{Kg} / \mathrm{liter})$ & 0.8932 \\
2 & Total sulfur $(\% \mathrm{wt})$ & 2.88 \\
3 & Total Nitrogen $(\mathrm{ppm} w \mathrm{wt})$ & 320 \\
4 & Acidity $(\mathrm{mg} \mathrm{KOH} \mathrm{g})$ & 0.1 \\
5 & Viscosity at $60 \% .(\mathrm{cSt}))$ & 25.15 \\
6 & Pour point $\left({ }^{\circ} \mathrm{C}\right)$ & 6 \\
7 & Cloud point $\left({ }^{\circ} \mathrm{C}\right)$ & 8 \\
8 & Aniline point $\left({ }^{\circ} \mathrm{C}\right)$ & 71.8 \\
\hline
\end{tabular}




\subsubsection{Emulsifying Agent}

The important step for forming stable emulsion was to select the suitable surfactant blend, Span 80 and Tween 80 that were used in the present work. The Specifications of the surfactants are shown in Table 2.

\subsection{Experimental Methods}

\subsubsection{Process of Emulsification}

WiDNE were generated by dispersing water content into diesel fuel according to Table 3. The formation was done in three steps:

1) Surfactants Tween $80(\mathrm{HLB}=15)$ and Span $80(\mathrm{HLB}=4.3)$ were blended to get the desired Tween80/Span80 ratio $(\mathrm{HLB}=8)$.

2) The prepared blend was added into the diesel fuel, and homogenized at 15,000 rpm for $10 \mathrm{~min}$.

3) Distilled water was added gradually, into the mixture of diesel and surfactants, and mixed according to Table 3.

\subsubsection{CCD Experimental Design}

Consequently CCD is a combination of both mathematical and statistical technique used to design experiments; evaluate the factors of process; obtaining the model; interaction between variables and find optimum condition to analyze the problem [21] [22]. Response Surface Methodology RSM was applied to study the impacts of the independent factors: applied water percent (w\%), Tween80/Span80 ratio (TS\%), mixing time ( $\mathrm{min})$, homogenizer speed rpm, alkalinity $(\mathrm{pH})$ and HLB of WiDNE. The experiments were designed using a 54 factorial with five central points as shown in Table 3. The individual experiments were carried out in random order

\section{Results and Discussion}

\subsection{Analysis of Variance}

The sum of square sequential model was used to compare different models. It showed the statistical significance of adding new terms step by step in increasing order. It provided accounts of variation and associated P-values (Prob $>$ F). The model was selected based on the highest order that was significant ( $\mathrm{P}$-value small) and not aliased, on lack of fit (P-value $>0.10$ ) and reasonable agreement between adjusted R-squared and predicted R-squared (within 0.2 of each other). The summary table of the sequential model sum of square is shown on Table 4.

Table 2. Properties of the surfactants.

\begin{tabular}{ccc}
\hline & Span 80 & Tween 80 \\
symbol & $\mathrm{S}$ & $\mathrm{T}$ \\
Appearance & Brown viscous & Amber sticky \\
$\mathrm{Mwt}$ & 428.61 & 1310 \\
Density $(\mathrm{g} / \mathrm{ml}) @ 20^{\circ} \mathrm{C}$ & 0.99 & 1.08 \\
$\mathrm{HLB}$ & 4.3 & 15 \\
\hline
\end{tabular}


Table 3. The experiments design trial used for WiDNE fuel preparation.

\begin{tabular}{|c|c|c|c|c|c|c|c|}
\hline NO. & $\mathrm{W} \%$ & HLB & TS\% & TIME(min) & $\mathrm{rpm}$ & $\mathrm{pH}$ & $\mathrm{D}(\mathrm{nm})$ \\
\hline 1 & 18 & 5.7 & 2.6 & 40 & 17,000 & 9.8 & 30 \\
\hline 2 & 18 & 5.7 & 2.6 & 30 & 17,000 & 11.2 & 29.2 \\
\hline 3 & 12 & 5.7 & 3.4 & 40 & 17,000 & 9.8 & 21 \\
\hline 4 & 12 & 5.3 & 3.4 & 30 & 13,000 & 9.8 & 27.3 \\
\hline 5 & 12 & 5.7 & 3.4 & 30 & 17,000 & 11.2 & 22 \\
\hline 6 & 18 & 5.3 & 2.6 & 30 & 13,000 & 9.8 & 31.3 \\
\hline 7 & 18 & 5.3 & 3.4 & 30 & 17,000 & 11.2 & 27 \\
\hline 8 & 18 & 5.3 & 2.6 & 40 & 13,000 & 11.2 & 33 \\
\hline 9 & 12 & 5.3 & 2.6 & 40 & 17,000 & 9.8 & 25 \\
\hline 10 & 12 & 5.3 & 2.6 & 30 & 17,000 & 11.2 & 24.3 \\
\hline 11 & 15 & 5.5 & 3 & 35 & 15,000 & 10.5 & 27 \\
\hline 12 & 12 & 5.7 & 2.6 & 40 & 13,000 & 11.2 & 29 \\
\hline 13 & 18 & 5.7 & 3.4 & 30 & 13,000 & 9.8 & 29 \\
\hline 14 & 18 & 5.3 & 3.4 & 40 & 17,000 & 9.8 & 26.5 \\
\hline 15 & 18 & 5.7 & 3.4 & 40 & 13,000 & 11.2 & 27 \\
\hline 16 & 12 & 5.7 & 2.6 & 30 & 13,000 & 9.8 & 26.1 \\
\hline 17 & 15 & 5.5 & 3 & 35 & 15,000 & 10.5 & 27.5 \\
\hline 18 & 15 & 5.5 & 3 & 35 & 15,000 & 10.5 & 27 \\
\hline 19 & 12 & 5.3 & 3.4 & 40 & 13,000 & 11.2 & 24.2 \\
\hline 20 & 15 & 5.5 & 3 & 35 & 15,000 & 10.5 & 28 \\
\hline 21 & 12 & 5.3 & 2.6 & 40 & 13,000 & 9.8 & 24.1 \\
\hline 22 & 18 & 5.3 & 3.4 & 30 & 13,000 & 11.2 & 32 \\
\hline 23 & 18 & 5.7 & 3.4 & 30 & 17,000 & 9.8 & 27.3 \\
\hline 24 & 12 & 5.3 & 2.6 & 30 & 13,000 & 11.2 & 30 \\
\hline 25 & 12 & 5.7 & 3.4 & 30 & 13,000 & 11.2 & 27 \\
\hline 26 & 18 & 5.7 & 3.4 & 40 & 17,000 & 11.2 & 22.3 \\
\hline 27 & 12 & 5.3 & 3.4 & 30 & 17,000 & 9.8 & 25 \\
\hline 28 & 12 & 5.7 & 3.4 & 40 & 13,000 & 9.8 & 23.5 \\
\hline 29 & 18 & 5.7 & 2.6 & 30 & 13,000 & 11.2 & 32.3 \\
\hline 30 & 15 & 5.5 & 3 & 35 & 15,000 & 10.5 & 28 \\
\hline 31 & 15 & 5.5 & 3 & 35 & 15,000 & 10.5 & 27.9 \\
\hline 32 & 12 & 5.7 & 2.6 & 30 & 17,000 & 9.8 & 26 \\
\hline 33 & 18 & 5.3 & 2.6 & 30 & 17,000 & 9.8 & 33 \\
\hline 34 & 15 & 5.5 & 3 & 35 & 15,000 & 10.5 & 28 \\
\hline 35 & 18 & 5.3 & 2.6 & 40 & 17,000 & 11.2 & 30.2 \\
\hline 36 & 12 & 5.7 & 2.6 & 40 & 17,000 & 11.2 & 25.04 \\
\hline
\end{tabular}




\section{Continued}

\begin{tabular}{|c|c|c|c|c|c|c|c|}
\hline 37 & 18 & 5.3 & 3.4 & 40 & 13,000 & 9.8 & 30 \\
\hline 38 & 18 & 5.7 & 2.6 & 40 & 13,000 & 9.8 & 29 \\
\hline 39 & 15 & 5.5 & 3 & 35 & 15,000 & 10.5 & 27 \\
\hline 40 & 12 & 5.3 & 3.4 & 40 & 17,000 & 11.2 & 21 \\
\hline 41 & 15 & 6.5 & 3 & 35 & 15,000 & 10.5 & 25 \\
\hline 42 & 15 & 5.5 & 3 & 35 & 25,000 & 10.5 & 21.7 \\
\hline 43 & 15 & 5.5 & 3 & 35 & 15,000 & 7.5 & 30 \\
\hline 44 & 15 & 5.5 & 3 & 35 & 15,000 & 13.5 & 28 \\
\hline 45 & 15 & 5.5 & 5 & 35 & 15,000 & 10.5 & 29.5 \\
\hline 46 & 0 & 5.5 & 3 & 35 & 15,000 & 10.5 & 2 \\
\hline 47 & 15 & 4.5 & 3 & 35 & 15,000 & 10.5 & 30 \\
\hline 48 & 15 & 5.5 & 3 & 35 & 5000 & 10.5 & 35 \\
\hline 49 & 15 & 5.5 & 3 & 35 & 15,000 & 10.5 & 30.1 \\
\hline 50 & 15 & 5.5 & 3 & 35 & 15,000 & 10.5 & 28 \\
\hline 51 & 30 & 5.5 & 3 & 35 & 15,000 & 10.5 & 29 \\
\hline 52 & 15 & 5.5 & 1.5 & 35 & 15,000 & 10.5 & 36.5 \\
\hline 53 & 15 & 5.5 & 3 & 60 & 15,000 & 10.5 & 29.5 \\
\hline 54 & 15 & 5.5 & 3 & 10 & 15,000 & 10.5 & 42 \\
\hline
\end{tabular}

Table 4. Analysis of variance of the regression coefficients of the quadratic equation for the droplets size.

\begin{tabular}{ccccccc}
\hline Source & $\begin{array}{c}\text { Sum } \\
\text { of Squares }\end{array}$ & df & $\begin{array}{c}\text { Mean } \\
\text { Square }\end{array}$ & $\begin{array}{c}\text { F } \\
\text { Value }\end{array}$ & $\begin{array}{c}\text { p-value } \\
\text { Prob }>\text { F }\end{array}$ & $\begin{array}{c}\text { Model } \\
\text { Significant }\end{array}$ \\
\hline Block & 12.88 & 2 & 6.44 & & & \\
Model & 1401.79 & 27 & 51.92 & 52.82 & $<0.0001$ & Significant \\
A-w\% & 505.33 & 1 & 505.33 & 514.07 & $<0.0001$ & \\
B-HLB & 22.72 & 1 & 22.72 & 23.11 & $<0.0001$ & \\
C-TS\% & 99.21 & 1 & 99.21 & 100.93 & $<0.0001$ \\
D-TIME & 99.79 & 1 & 99.79 & 101.52 & $<0.0001$ \\
E-RPM & 138.22 & 1 & 138.22 & 140.61 & $<0.0001$ & \\
F-pH & 0.74 & 1 & 0.74 & 0.75 & 0.3942 & \\
AB & 7.64 & 1 & 7.64 & 7.78 & 0.0102 & \\
AC & 2.18 & 1 & 2.18 & 2.22 & 0.1491 & \\
AD & 0.097 & 1 & 0.097 & 0.098 & 0.7564 & \\
AE & 0.44 & 1 & 0.44 & 0.45 & 0.509 & \\
AF & 1.82 & 1 & 1.82 & 1.86 & 0.1858 & \\
BC & 2.9 & 1 & 2.9 & 2.95 & 0.0985 & 0.5001 \\
BD & 0.46 & 1 & 0.46 & 0.47 & \\
\hline
\end{tabular}




\section{Continued}

\begin{tabular}{cccccc}
\hline BE & $8.00 \mathrm{E}-04$ & 1 & $8.00 \mathrm{E}-04$ & $8.14 \mathrm{E}-04$ & 0.9775 \\
BF & 0.19 & 1 & 0.19 & 0.19 & 0.6674 \\
CD & 6.34 & 1 & 6.34 & 6.45 & 0.018 \\
CE & 7.84 & 1 & 7.84 & 7.98 & 0.0094 \\
CF & 7.64 & 1 & 7.64 & 7.78 & 0.0102 \\
DE & 0.19 & 1 & 0.19 & 0.19 & 0.6674 \\
DF & 0.46 & 1 & 0.46 & 0.47 & 0.5001 \\
EF & 22.71 & 1 & 22.71 & 23.11 & $<0.0001$ \\
A2 & 212.62 & 1 & 212.62 & 216.3 & $<0.0001$ \\
B2 & 2.98 & 1 & 2.98 & 3.03 & 0.0947 \\
C2 & 27.26 & 1 & 27.26 & 27.73 & $<0.0001$ \\
D2 & 50.61 & 1 & 50.61 & 51.48 & $<0.0001$ \\
E2 & 0.66 & 1 & 0.66 & 0.67 & 0.4195 \\
F2 & 0.017 & 1 & 0.017 & 0.017 & 0.8962 \\
Residual & 23.59 & 24 & 0.98 & & \\
Lack of Fit & 19.99 & 17 & 1.18 & 2.29 & 0.1348 \\
Pure Error & 3.6 & 7 & 0.51 & & \\
Total Corrected & 1438.26 & 53 & & & \\
for the means & & & & & \\
\hline
\end{tabular}

The lack of fit tests was included because extra design points beyond what was needed for the model were involved to provide estimation of pure error. Since it was not desirable, so a small $\mathrm{F}$ value and probability greater than 0.1 were desired.

Data obtained in Table 5 was analyzed using the CCD. The analysis result by ANOVA was with $95 \%$ confidence displaying $F$ value model was 52.82 and if the value of $\mathrm{P}$ lower than 0.05 , that means the predicted model was substantial.

The appropriate of the models relied on the value of $\mathrm{R}^{2}$ coefficient, the model recording $R^{2}=98.34 \%$. Furthermore, a suitable agreement with the adjusted coefficient of determination was discovered.

In this study, the Adj- $\mathrm{R}^{2}$ value of $96.48 \%$ and Pred. $\mathrm{R}^{2} 84.40 \%$ were obtained. Both values of $A d j-R^{2}$ and $R^{2}$ very adjacent to 1.0 were high and supported a high closing between the predicted and the observed values.

The Pred- $R^{2}$ of $84.40 \%$ was in rational agreement with the Adj. $R^{2}$ of $96.48 \%$; the difference was less than 0.2. Value of lake of fit was $0.1348>0.05$ (not significant) showing that the hypothesis of significance of fitting was rejected for RSM method. The model with p-value of 0.0001 means that there was only $0.01 \%$ chance that the F-value of the model. Response surface model equation for regression was in actual units to optimum diameter size by using Design Expert software as illustrated in the Equation (1). 
Table 5. ANOVA model adequacy.

\begin{tabular}{cc}
\hline Statistical analysis & Values \\
\hline R-Squared & 0.9834 \\
Adj. R-Squared & 0.9648 \\
Pred. R-Squared & 0.8440 \\
Adeq. Precision & 51.660 \\
\hline
\end{tabular}

$$
\begin{aligned}
\mathrm{D}(\mathrm{nm})= & 27.93+2.48 \times \mathrm{A}-0.53 \times \mathrm{B}-1.25 \times \mathrm{C}-1.10 \times \mathrm{D} \\
& -1.29 \times \mathrm{E}-0.10 \times \mathrm{F}-0.48 \times \mathrm{AB}-0.2 \times \mathrm{AC}+0.05 \times \mathrm{AD} \\
& +0.11 \times \mathrm{AE}-0.23 \times \mathrm{AF}-0.30 \times \mathrm{BC}+0.12 \times \mathrm{BD}-0.005 \times \mathrm{BE} \\
& +0.07 \times \mathrm{BF}-0.44 \times \mathrm{CD}-0.49 \times \mathrm{CE}-0.48 \times \mathrm{CF}+0.07 \times \mathrm{DE} \\
& +0.12 \times \mathrm{DF}-0.84 \times \mathrm{EF}-0.54 \times \mathrm{A}^{2}-0.06 \times \mathrm{B}^{2}+0.24 \times \mathrm{C}^{2} \\
& +0.26 \times \mathrm{D}^{2}-0.03 \times \mathrm{E}^{2}-0.006 \times \mathrm{F}^{2}
\end{aligned}
$$

Equation (1) is in terms of coded variables that can be used for making expectations toward the responses to each factor at given levels. Negative value for individual factor in equation means in reducing droplets size. By default, the low levels of the factors were coded as -1 and the high levels of the factors interaction were coded as +1 . The coded equation was useful for evaluating the relative effluent of the variables by comparing to the coefficients factor, where water $\mathrm{W} \%$ (A), HLB (B), TS\% (C), mixing time (min) (D), mixing speed rpm (E), and $\mathrm{pH}$ (F).

It was observed from Figure 1 that the extent of proximity of the results with the expected values, through which we concluded that the mathematical relationship between the factors affecting the size of droplets already corresponds to reality and confirmed the compatibility of the results of the process and arithmetic.

The results displayed fulfilled with the model assumptions of ANOVA. It indicates no sign presented that the error terms were correlated with each other.

\subsection{Effect of Emulsification Variables}

The most significant step in the preparation of WiDNE is selection of an appropriate variables and the effect of each one on the response. In this study, RSM method with six variables was selected in order to understand the impacts on droplet size. Each of these variables had a different effluent and limited impact except $\mathrm{W} \%$, all other factors were associated to reduce droplet size.

Figure 2 shows the effect and interaction of factors on the droplets size starting from the most influential factor and ending with the least impact. It has been found that the rpm has a direct impact on the size of droplets.

Therefore, the $3 \mathrm{D}$ plots are the best method for illustrating the interaction between variables and effect of each others as can be shown in Figure 3.

In order to clarify the impact of the independent variables according to the results, response surface and $3 \mathrm{D}$ plots of the quadratic polynomial model were 


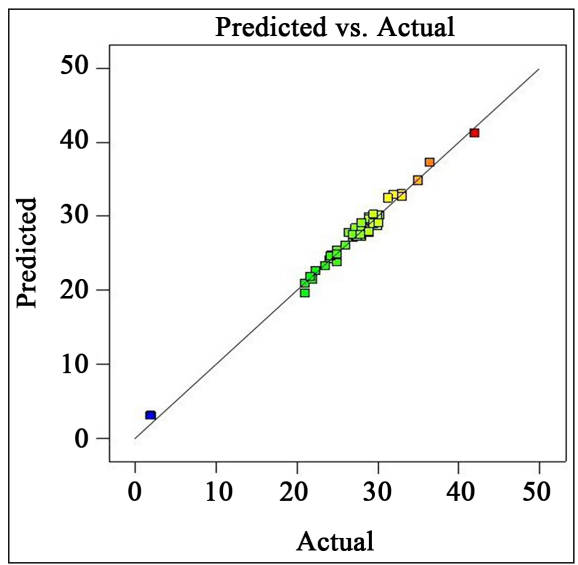

Figure 1. Predicted vs. actual result of droplet sizes.

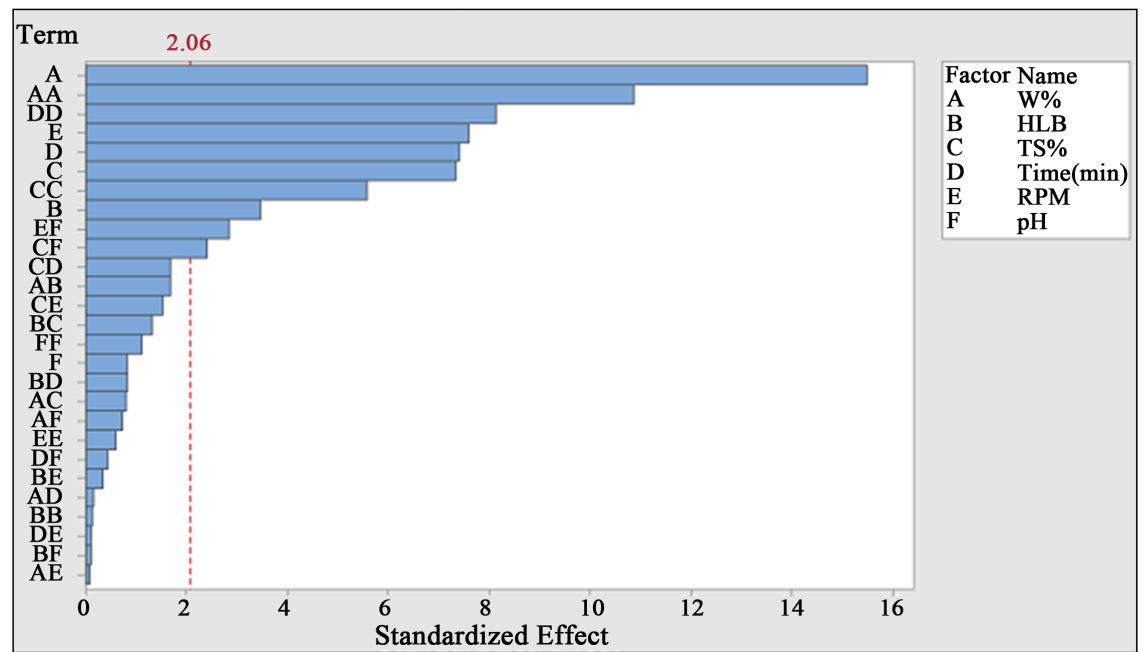

Figure 2. Pare to chart of the standardized effects.

created by varying two of independent variables (within the experimental range) for studying the combination effect on response.

Thus the Figures were generated by varying two variables in $\mathrm{x}$ and $\mathrm{y}$ axis while holding the other variables at optimum values. In this research, WiDNE fuels were prepared by two steps, the first step was prepared of a WiDNE at low rotating speed. Then, high energy homogenizer process was used to additionally decrease in the droplet size. The resistance of droplets to deformation was determined by the surface tension [23] [24].

The coalescence rate of droplets is specified by the ability of emulsifiers that are adsorbed on the surface of droplets, which is ruled by the concentration of surfactants and surface activity Figure 3(a) was plotted by varying the water ratio and surfactants HLB while maintaining the other variables constant.

According to Equation (1), the coefficient value of HLB was -0.53 for WiDNE preparation. The higher value means this variable is significant. The negative value means that HLB leads to decrease the droplet size but in less effect than positive. 


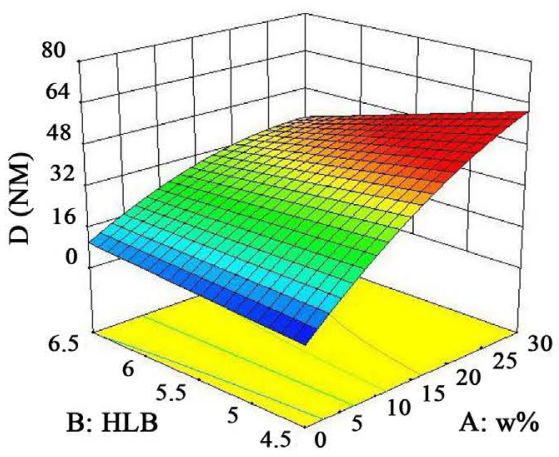

(a)

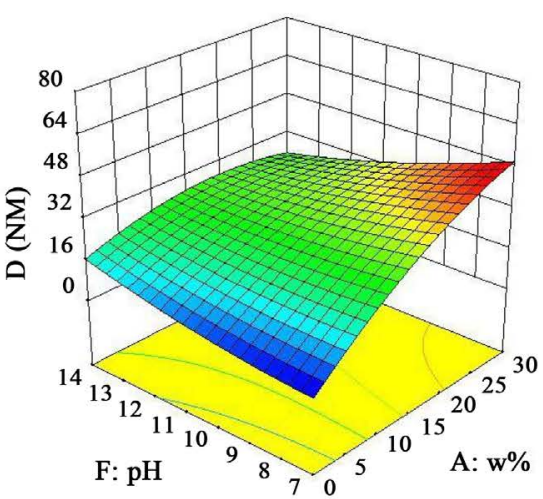

(c)

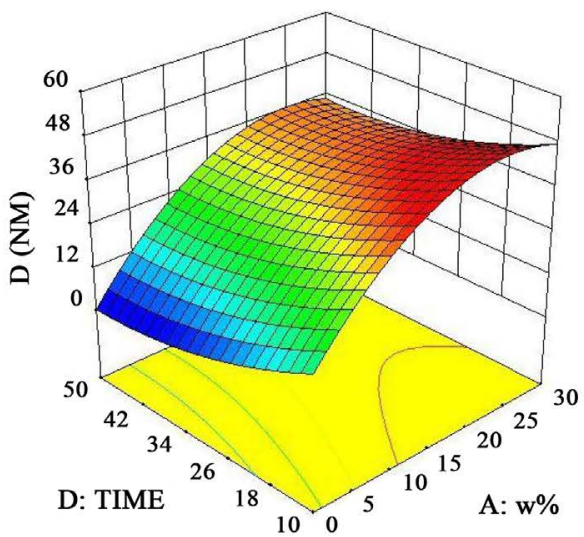

(e)

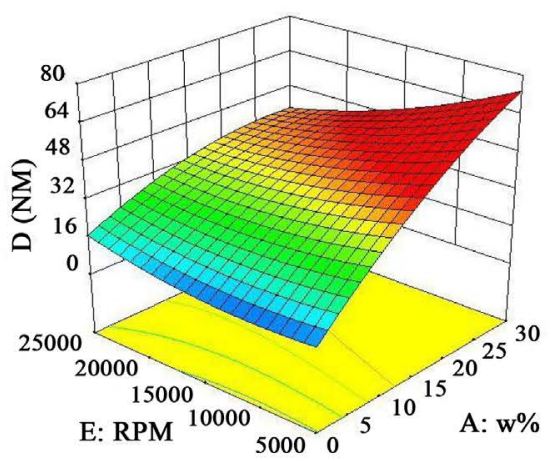

(b)

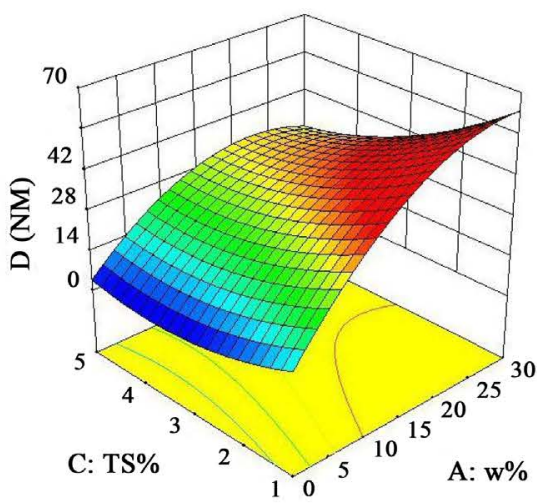

(d)

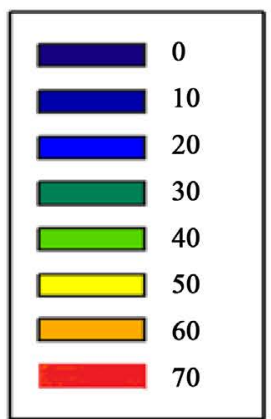

Figure 3. Interaction of factors with water percent with respect to droplet diameter.

Figure 3(a) illustrates the relationship between HLB and W\% (-0.48), the changes in droplet size are in very narrow and that can be confirmed by Equation (1). The lower interaction coefficient found between HLB and W\%. The rpm are directly effect on reducing droplet size. It can be shown according to Equation (1) -0.1 decreasing, while its interaction can more impact on response, as shown in Figure $3(\mathrm{~b})$ and by Equation (1) $+0.11 \mathrm{rpm}$. $\mathrm{pH}$ of dispersed water into diesel fuel is shown in Figure 3(c) that limited to effect on droplets size.

The surfactants role is very central in WiDNE system. It implements two functions. First, it will increase the interaction between the two immiscible sys- 
tems; diesel fuel and water by decreasing interfacial tension. Second, it can be improved to stabilize the WiDNE system. Stability behavior of emulsions is highly reliant on concentration of surfactant and its nature.

Surfactant molecules organize themselves near interfacial film between water dispersed phase and diesel fuel a continuous phase, in order to stabilize the water dispersed droplets into the diesel phase. High concentration of surfactants avoids the integration of water droplets [16] [25] [26] [27]. It is observed from Figure 3(d) how readily surfactant stabilizing dispersed phase in diesel fuel. According to Equation (1) the impact of mixed surfactant is -1.25 . More increasing the time of splitting droplets to mixing, much less size of droplets will be obtained, but this factor will effect to specific limit and more than it would be useless or don't have benefit economically. The effluents of mixing time are investigated through Figure 3(e) combined with W\% on droplets size.

\subsection{Optimum Stability Condition Specifications}

Obtaining the best conditions for the WiDNE fuel preparation process is one of the advantages of using this study. As shown in Figure 4, the optimum conditions of prepared WiDNE according to response surface method (RSM) were water content $11.9997 \%$, surfactant concentration 4.9993\%, HLB 6, RPM 15,000, mixing time $30 \mathrm{~min}$ and $\mathrm{pH}$ 10.5001. This study has relied on Design Expert Software to locate the optimal situations by composite desirability, from which $25.2253 \mathrm{~nm}$ chosen to be the optimum droplet size which exhibited good stability without phase separation during two weeks. The stability in the WiDNE is determined by the water droplet size inside the diesel phase.

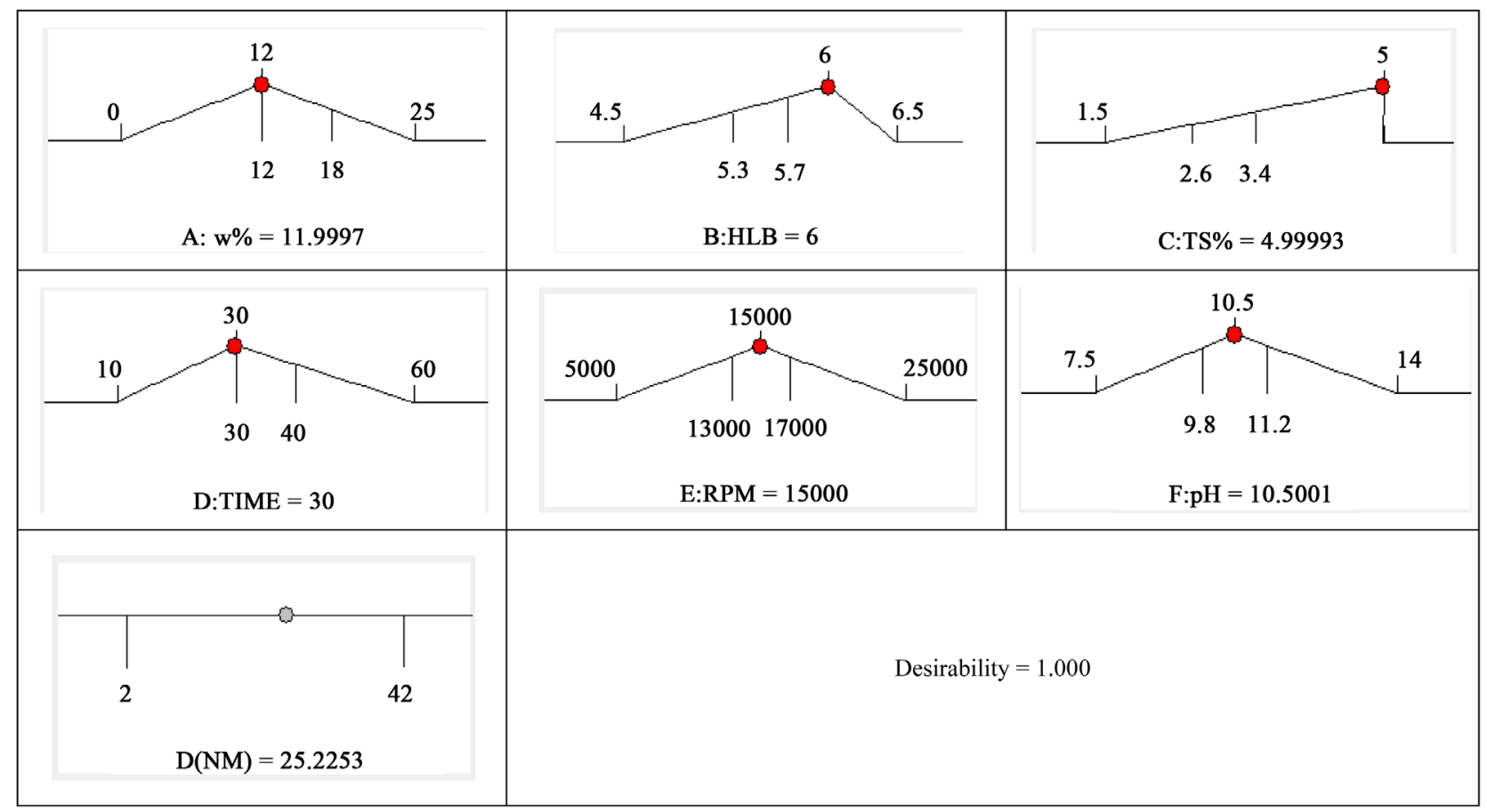

Figure 4. The best conditions for stability of prepared WiDNE fuel. 
Figure 5 shows the measured water effective diameter dispersed inside the WiDNE fuel. The measured diameter is $26 \mathrm{~nm}$, with 0.0297 errors between actual conditions and measured by the Design Expert Software.

Optimum blend of prepared WiDNE fuel are compared with conventional diesel, as shown in Table 6.

The optimum water ratio was $12 \%$, based on weight percent. The proportion of water inside the emulsified fuel must be kept within the specified limits, because the increase in the proportion of water quantity leads to a decrease in heat of combustion and affect the properties of fuel ignition.

Surfactant plays an important role in the stability of the WiDNE. This role lies in the ability of the surfaces to reduce the interfacial tension between the two liquids and facilitate the process of emulsification and protect droplets from adhesion, aggregations and thus protection from separation.

The exposure time of water droplet within the WiDNE fuel has a direct relationship to the conditions and the rotation speed. Increasing the time led drops to homogeneity and uniform distribution within the emulsion, but this will be limited if exceeded the optimum time, where considered consumed in energy and time. The optimum time was chosen to be $30 \mathrm{~min}$. The rpm leads to the rupture of the droplets to smallest size. Therefore, it is the main factor affecting the size of droplets; the best speed is chosen to be $15,000 \mathrm{rpm}$. Alkalinity $\mathrm{pH}$ does not have a strong effect on droplets size but has interaction with other factors; it is optimized to be 10.5 .

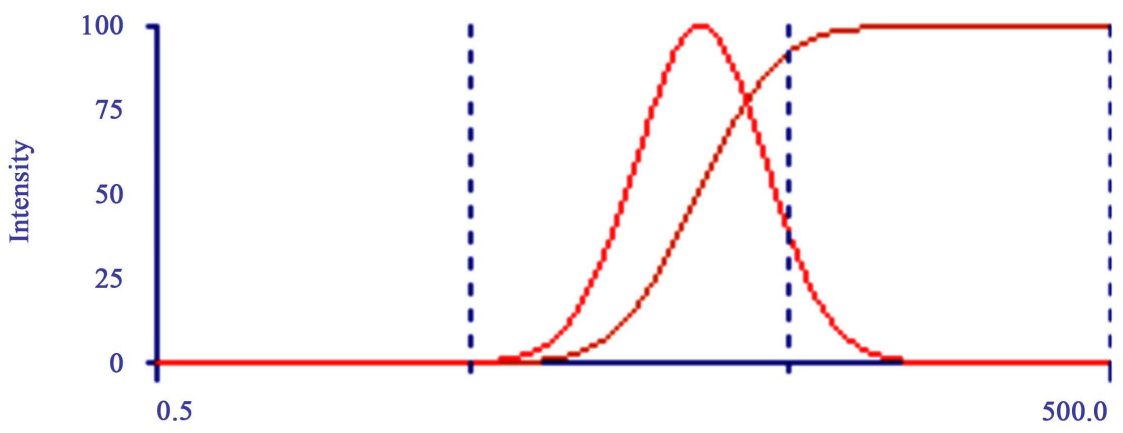

Diameter (nm)

Figure 5. Measured effective diameter for WiDNE fuel at the best conditions.

Table 6. Properties of conventional diesel fuel and the optimum prepared WiDNE.

\begin{tabular}{ccc}
\hline Properties & Diesel fuel & WiDNE fuel \\
\hline Calorific value $(\mathrm{kJ} / \mathrm{kg})$ & 44,800 & 38,850 \\
Flash point $\left({ }^{\circ} \mathrm{C}\right)$ & 54 & 61 \\
Viscosity at $40^{\circ} \mathrm{C}(\mathrm{cSt})$ & 3.268 & 4.56 \\
Pour point $\left({ }^{\circ} \mathrm{C}\right)$ & 9 & 7 \\
Density $\mathrm{g} / \mathrm{cm}^{3}$ & 0.87 & 0.882 \\
\hline
\end{tabular}




\subsection{WiDNE Fuel Properties}

\subsubsection{Calorific Value}

The variation in the calorific value of WiDNE fuel is shown in Table 6. The calorific value was reduced from 44,800 to $38,850 \mathrm{~kJ} / \mathrm{kg}$.The less calorific value observed due to the content of $12 \%$ water in WiDNE fuel. Water reduces the calorific value and then decreases the heat of reactions that produce high toxicity gases. The improvement in calorific value of WiDNE fuel could be observed with the addition of specific nanocatalyst [28].

\subsubsection{Flash Point}

Flash point is an indication of the fuel's volatility. For safe handling of liquid fuel, it should always have high value. The influence of water content on flash point of WiDNE fuel is shown in Table 6 determined using Pensky Martin Apparatus. It was observed that flash point of WiDNE fuel increased from $54^{\circ} \mathrm{C}$ to $61^{\circ} \mathrm{C}$ with respect to water percent.

\subsubsection{Viscosity}

The effect of the presence of water on the viscosity of WiDNE fuel is shown in Table 5. It was observed that viscosity increases from 3.268 to $4.56 \mathrm{cSt}$. The increasing in viscosity leads to more power requirement for pumping of fuel and poor atomization.

\subsubsection{Density}

The impact of water on density of WiDNE fuel is shown in Table 5. Density was increased from $0.87 \mathrm{~g} / \mathrm{cm}^{3}$ to $0.882 \mathrm{~g} / \mathrm{cm}^{3}$ for WiDNE. It is known that the water is heavier than diesel fuel. The impact of water is obvious in increases the density when blending with diesel. However, more fuel density means less volume will be taken for storing purpose.

\subsubsection{Pour Point}

Pour point of WiDNE fuel $+7^{\circ} \mathrm{C}$ were less compared with net diesel $+9^{\circ} \mathrm{C}$. Increasing water content on WiDNE fuel caused reduction in pour point as shown in Table 6. With formation of WiDNE fuel, this pour point can be lowered significantly in order to confirm safe transportation of these types of oils.

\section{Conclusions}

1) Response surface methodology (RSM) was used to enhance process variables for preparation of WiDNE fuel.

2) Surfactant concentration has very positive effect on emulsion stability.

3) Increasing in water content decreased the emulsion stability.

4) Mixing and time have enhanced the stability significantly up to a certain limit beyond which it remains the same.

\section{References}

[1] Dickinson, E. (1992) An Introduction to Food Colloids. Oxford University Press, 
Oxford. https://doi.org/10.1002/food.19920360540

[2] Mc Clements, D.J. (2005) Food Emulsions: Principles, Practice, and Techniques. 2nd Edition, CRC Press, Boca Raton, FL. https://doi.org/10.1016/j.foodhyd.2005.05.001

[3] Shinoda, K. and Saito, H. (1968) The Effect of Temperature on the Phase Equilibria and the Types of Dispersions of the Ternary System Composed of water, Cyclohexane, and Nonionic Surfactant. Journal of Colloid and Interface Science, 26, 70-74. https://doi.org/10.1016/0021-9797(68)90273-7

[4] Forgiarini, A., Esquena, J., Gonza'lez, C. and Solans, C. (2001) Formation of Nano-Emulsions by Low-Energy Emulsification Methods at Constant Temperature. Langmuir, 17, 2076-2083. https://doi.org/10.1021/la001362n

[5] Wu, H.L., Ramachandran, C., Weiner, N.D. and Roessler, B.J. (2001) Topical Transport of Hydrophilic Compounds Using Water-in-Oil Nanoemulsions. International Journal of Pharmaceutics, 220, 63-75. https://doi.org/10.1016/S0378-5173(01)00671-8

[6] Taha, S. Al-Saidan, Samy, A.M. and Khan, M.A. (2004) Preparation and in Vitro. Characterization of Self-Nanoemulsified Drug Delivery System (SNEDDS) of AllTransretinol Acetate. International Journal of Pharmaceutics, 285, 109-119. https://doi.org/10.1016/j.ijpharm.2004.03.034

[7] Sonneville-Aubrun, O., Simonnet, J.T. and L'Alloret, F. (2004) Nanoemulsions: A New Vehicle for Skincare Products. Advances in Colloid and Interface Science, 108/109, 145-149. https://doi.org/10.1016/j.cis.2003.10.026

[8] Lee, G.W.J. and Tadros, T.F. (1982) Formation and Stability of Emulsions Produced by Dilution of Emulsifiable Concentrates. Part I. An Investigation of the Dispersion on Dilution of Emulsifiable Concentrates Containing Cationic and Non-Ionic Surfactants. Colloids and Surfaces, 5, 105-115. https://doi.org/10.1016/0166-6622(82)80066-8

[9] Liu, X., Guan, Y., Ma, Z. and Liu, H. (2004) Surface Modification and Characterization of Magnetic Polymer Nanospheres Prepared by Miniemulsion Polymerization. Langmuir, 20, 10278-10282. https://doi.org/10.1021/la0491908

[10] Tomomasa, S., Kochi, M. and Nakajima, H. (1988) Microemulsion Formation in Two Phase Region Preparation Method and Stability. Journal of Japan Oil Chemists' Society, 37, 1012-1017.

[11] Rang, M.J. and Miller, C.A. (1999) Spontaneous Emulsification of Oils Containing Hydrocarbon, Nonionic Surfactant, and Oleyl Alcohol. Journal of Colloid and Interface Science, 209, 179-192. https://doi.org/10.1006/jcis.1998.5865

[12] Pons, R., Carrera, I., Caelles, J., Rouch, J. and Panizza, P. (2003) Formation and Properties of Miniemulsions Formed by Microemulsions Dilution. Advances in Colloid and Interface Science, 106, 129-146. https://doi.org/10.1016/S0001-8686(03)00108-8

[13] Lamaallam, S., Bataller, H., Dicharry, C. and Lachaise, J. (2005) Formation and Stability of Mini Emulsions Produced by Dispersion of Water/Oil/Surfactants Concentrates in an Application of Nanotechnology in Drug Delivery. Colloids and Surfaces A: Physicochemical and Engineering Aspects, 270-271, 44-51. https://doi.org/10.1016/j.colsurfa.2005.05.035

[14] Forgiarini, A., Esquena, J., Gonza'lez, C. and Solans, C. (2000) Studies of the Relation between Phase Behavior and Emulsification Methods with Nanoemulsion Formation. Progress in Colloid and Polymer Science, 115, 36-39. https://doi.org/10.1007/3-540-46545-6_8 
[15] Forgiarini, A., Esquena, J., Gonza'lez, C. and Solans, C. (2001) Formation and Stability of Nano-Emulsions in Mixed Nonionic Surfactant Systems. Progress in Colloid and Polymer Science, 118, 184-189. https://doi.org/10.1007/3-540-45725-9_42

[16] Shinoda, K. and Saito, H. (1968) The Effect of Temperature on the Phase Equilibria and the Types of Dispersions of the Ternary System Composed of Water, Cyclohexane, and Nonionic Surfactant. Journal of Colloid and Interface Science, 26, 70-74. https://doi.org/10.1016/0021-9797(68)90273-7

[17] Morales, D., Gutierrez, J.M., Garcia-Celma, J.M. and Solans, C. (2003) A Study of the Relation between Bicontinuous Microemulsions and Oil/Water Nano-Emulsion Formation. Langmuir, 19, 7196-7200. https://doi.org/10.1021/la0300737

[18] Wu, C.F.J. and Hamada, M.S. (2009) Experiments: Planning, Analysis, and Parameter Design Optimization. 2nd Edition, Wiley, Hoboken.

[19] Vereda Alonso, E., García de Torres, A., Siles Cordero, M.T. and Cano Pavón, J.M. (2011) Multivariate Optimization of the Synthesis and of the Microwave Dissolution of Biomorphic Silicon Carbide Ceramics. Microchemical Journal, 97, 101-108. https://doi.org/10.1016/j.microc.2010.07.012

[20] Milan, D.K., Nataša, M.J., Olivera, S.S., Katarina, M.R., Petar, S.M. and Vlada, B.V. (2013) Optimization of Hempseed Oil Extraction by n-Hexane. Industrial Crops and Products, 48, 133-143. https://doi.org/10.1016/j.indcrop.2013.04.028

[21] Myers, R.H., Montgomery, D.C. and Anderson-Cook, C.M. (2002) Response Surface Methodology: Process and Product Optimization Using Designed Experiments. 2nd Edition, Wiley, Hoboken.

[22] Jamil, S.M., Ali, M.W., Ripin, A. and Ahmad, A. (2015) Adsorption of Sodium, Magnesium, Calcium and Zinc from Recovered Base Oil of Used Lubricants Using Chitosan. Journal of Applied Sciences, 15, 516-523.

https://scialert.net/abstract/?doi=jas.2015.516.523 https://doi.org/10.3923/jas.2015.516.523

[23] Kentish, S., Wooster, T.J., Ashokkumar, M., Balachandran, S., Mawson, R. and Simons, L. (2008) The Use of Ultrasonics for Nanoemulsion Preparation. Innovative Food Science and Emerging Technologies, 9, 170-175.

https://doi.org/10.1016/j.ifset.2007.07.005

[24] Tadros, T., Izquierdo, P., Esquena, J. and Solans, C. (2004) Formation and Stability of Nanoemulsions. Advances in Colloid and Interface Science, 108, 303-318. https://doi.org/10.1016/j.cis.2003.10.023

[25] Sole, I., Maestro, A., Gonzalez, C., Solans, C. and Jose, M. (2006) Optimization of Nanoemulsion Preparation by Low-Energy Methods in an Ionic Surfactant System. Langmuir, 22, 8326-8332. https://doi.org/10.1021/la0613676

[26] Solans, C., Izquierdo, P., Noll, J., Azemer, N. and Garcia, M.J. (2005) Nanoemulsions. Current Opinion in Colloid and Interface Science, 10, 102-110. https://doi.org/10.1016/j.cocis.2005.06.004

[27] Fernandez, P., Andre, V., Riegger, J. and Kuhnle, A. (2004) Nanoemulsion Formation by Emulsion Phase Inversion. Colloids and Surfaces A: Physicochemical and Engineering Aspects, 251, 53-58. https://doi.org/10.1016/j.colsurfa.2004.09.029

[28] Singh, N.K. (2012) Experimental Investigation Diesel Emulsions as Fuel in Small Direct Injection Compression Ignition Engines. MIT International Journal of $\mathrm{Me}$ chanical Engineering, 2, 39-44. 